\title{
Modifikasi Permukaan Elemen Peredam Bising dengan Profil Berbentuk Prisma
}

\author{
Julius Indra Kusuma, Harjana, dan Iwan Yahya* \\ Laboratorium Riset Akustik (iARG), Jurusan Fisika, \\ Universitas Sebelas Maret (UNS), Jl. Ir.Sutami 36A Kentingan, Surakarta \\ *email:iyahya@mipa.uns.ac.id
}

Received 05-01-2016, Revised 28-02-2016, Accepted 15-03-2016, Published 20-04-2016

\section{ABSTRACT}

The influence of surface modification by using prism shaped profile on the sound absorption of absorber element was investigated experimentally. A prime number based configuration of the two types opened and closed type rism shaped profile inclusion was tested by using impedance tube according ASTM E1050 standard. The result shows that sound absorption at low frequency band below $200 \mathrm{~Hz}$ increased with the increasing of closed prism number. It is related to the coupling effect between the cavities of the absorber element and the prisms that changes reactance of the coupled structure. In the other side, a half wave resonance like effect occur on the use of opened prisms inclusion, which is increase the sound absorption performance at mid to high frequency range between $800 \mathrm{~Hz}$ to $1.25 \mathrm{kHz}$.

Keywords: prism-shaped inclusion, absorption coefficient, resonance, impedance tube method.

\section{ABSTRAK}

Dampak teknik modifikasi permukaan elemen peredam dengan struktur berbentuk prisma terhadap perubahan kinerja serapan bunyi disajikan dalam paper ini. Dua ragam prisma dengan tepi tertutup dan terbuka yang ditata dengan variasi dalam jumlah bilangan prima, 2, 5, dan 7 telah diuji secara eksperimental menggunakan metode tabung impedansi sesuai standar ASTM E-1050. Hasil pengujian menunjukkan bahwa efek dari rongga terkopel pada pemakaian prisma tertutup dapat meningkatkan kinerja serapan pada bentang frekuensi di bawah $200 \mathrm{~Hz}$, sementara prilaku yang menyerupai respon resonator setengah panjang gelombang terpicu pada pemasangan prisma terbuka yang memperbaiki kinerja serapan pada bentang frekuensi 800 $\mathrm{Hz}-1,25 \mathrm{kHz}$.

Kata Kunci: struktur prisma, koefisien serap, resonansi setengah panjang gelombang, tabung impedansi.

\section{PENDAHULUAN}

Struktur permukaan sound diffuser dapat meningkatkan kinerja peredam yang dipicumekanisme hamburan. Kajian teoretik maupun eksperimental tentang hal ini antara lain disajikan oleh Cox and d'Antonio dan Berkhout et al, yang kemudian menjadi salah satu acuan utama dalam perancangan peredam maupun sound diffuser ${ }^{[1-2]}$. Kajian oleh Pogson et al menyajikan teknik modifikasi permukaan dimana aspekdifusi yang ditinjau dikaitkan dengan dampak penempatansejumlahelemenberbentuk bola di depan quadratic residue diffuser (QRD) ${ }^{[3]}$. Sejumlah peneliti lain melakukan beberapa pendekatan berbeda untuk maksud serupa. Yang et al misalnya mengkaji pengaruh kombinasi dari beberapa rancangan diffuser yang disatukan terhadap kemampuannya menyerap bunyi. Analisis serupa juga dilakukan oleh Nutter et al yang menggunakan pendekatan energy density. Sementara Hanyu serta Groby et al berturut-turut melakukan pendekatan teoretik dan eksperimental atas dampak pemakaian bingkai padat sebagai penopang sound diffuser terhadap kinerja redamannya ${ }^{[4-7]}$. 
Selain beragam teknik tersebut di atas, paduan teknik resonansi, struktur berlubang dan pemakaian membran merupakan pilihan yang andal dalam peningkatan kinerja peredaman sound diffuser. Resonator Helmholtz maupun resonator seperempat panjang gelombang dapat menyajikan kinerja yang baik jika dipadukan dengan mekanisme redaman oleh membran ${ }^{[8-11]}$. Keutamaan yang dapat diperoleh dari pemakaian resonator adalah memberi peluang untuk mengatur respon frekuensi peredam baik dengan cara modifikasi jumlah struktur maupun panjang leher, atau perubahan volume rongga resonator ${ }^{[12-15]}$.

Paper ini menyajikan hasil kajian ekperimental atas teknik modifikasi elemen peredam dengan menempatkan struktur berbentuk prisma di permukaannya. Dalam hal ini digunakan dua ragam prisma dengan tepi tertutup dan terbuka yang ditata dalam tiga konfigurasi berbeda mengikuti jumlah bilangan prima. Dengan cara itu diharapkan akan terpicu mekanisme hamburan dan efek resonansi secara serempak dan menghasilkan kinerja serapan dalam bentang frekuensi yang lebih lebar. Fokus kajian adalah kinerja serapan sementara respon spasialnya tidak disajikan dalam paper ini.

\section{METODOLOGI}

\section{Pembuatan Desain Peredam}

Sampel peredam yang dikaji terbuat dari bahan yellow board dengan ketebalan $0.2 \mathrm{~cm}$ yang kemudian dibentuk menjadi kubus dengan dimensi panjang, lebar, dan tinggi masingmasing $5 \mathrm{~cm}$. Struktur berbentuk prisma yang juga terbuat dari bahan yang sama kemudian direkatkan di permukaan elemen peredam dalam konfigurasi sebagaimana disajikan dalam Gambar 1. Jumlah struktur yang direkatkan mengikuti aturan bilangan prima.

Pertimbangan yang mendasarinya adalah mengacu kepada konfigurasi dan prinsip kerja QRD. Dalam hal ini mekanisme resonansi seperempat panjang gelombang pada QRD digantikan oleh peran resonansi Helmholtz yang terpicu oleh gabungan struktur prisma dengan elemen kubus peredam yang menopangnya. Dengan demikian, diharapkan dapat diperoleh rancangan sound diffuser yang lebih ramping namun tetap memiliki respon spasial yang setara dengan QRD. Detil konfigurasi elemen peredam yang diuji disajikan dalam Tabel 1.

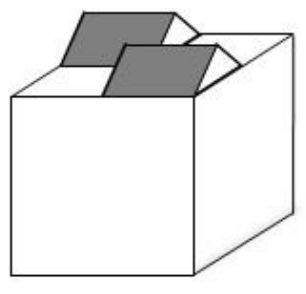

A

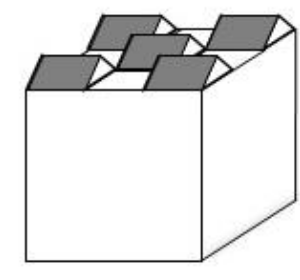

B

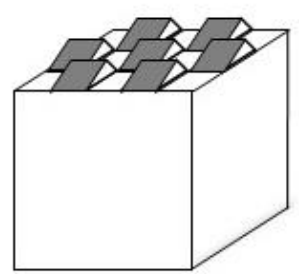

C

Gambar 1. Desain Peredam Dengan Penambahan Struktur Prisma

Tabel 1. Data Variasi Jumlah Struktur Prisma, Jumlah Resonator dan Kondisi Resonator

\begin{tabular}{cccc}
\hline No. & Jumlah Struktur Prisma & Jumlah Resonator & Kondisi Resonator \\
\hline 1. & 2 & 4 & Terbuka \\
2. & 2 & 4 & Tertutup \\
3. & 5 & 10 & Terbuka \\
4. & 5 & 10 & Tertutup \\
5. & 7 & 14 & Terbuka \\
6. & 7 & 14 & Tertutup \\
\hline
\end{tabular}




\section{Pengujian Koefisien Serapan Bunyi}

Pengujian koefisien serapan bunyi dilakukan secara eksperimental menggunakan tabung impedansi dua mikrofon mengacu kepada prosedur standar ASTM E 1050. Set up alat pengujian disajikan dalam Gambar 2.

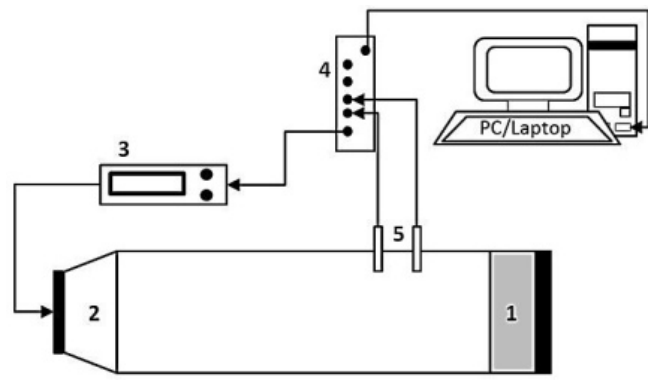

Gambar 2. Konfigurasi pengujian tabung impedansi dua mikrofon. Nomor (1) merupakan posisi sampel dan (2) adalah loudspeaker. Sementara Nomor (3), (4) dan (5) beturut-turut amplifier B\&K 2716C, B\&K Pulse dan mikrofon B\&K 4187.

Random noise dibangkitkan dengan generator pada B\&K LAN-XI 3160-A-042yang kemudian diperkuat dengan amplifier B\&K 2716C sebelum dipancarkan oleh loudspeaker pada tabung impedansi B\&K 4206. Bunyi yang merambat di dalam tabung itu kemudian terpantulkan oleh sampel uji yang ditempatkan di ujung lain tabung impedansi. Sebagian energi gelombang bunyi ini terserap oleh sampel uji. Kedua mikrofon yang satu sama lain terpisah oleh jarak sebesar $5 \mathrm{~cm}$ akan merekan tekanan bunyi yang terukur di dalam tabung. Data yang terekam tersebut diolah dengan teknik dekomposisi spektral berdasarkan analisis respon frekuensi sehingga dapat dipisahkan komponen gelombang datang dan komponen gelombang yang dipatulkan dari permukaan sampel uji.

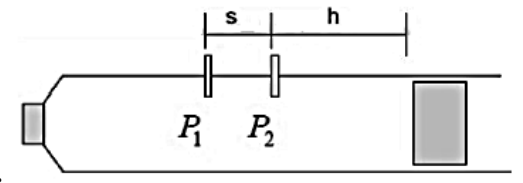

Gambar 3. Skema tabung impedansi dua mikrofon

Dengan membandingkan tekanan bunyi antara mikrofon 1 dan 2 sebagaimana tampak dalam Gambar (3) maka dapat diperoleh fungsi respon frekuensi diantara sinyal kedua mikrofon $^{[16]}$ :

$$
H_{12}=\frac{P_{2}}{P_{1}}=\frac{p_{i} e^{j k h}+p_{i} e^{-j k h}}{p_{i} e^{j k(h+s)}+p_{i} e^{-j k(h+s)}}
$$

Dari hubungan tersebut kemudian koefisien refleksi dapat disajikan dalam bentuk sebagai berikut,

$$
R=\frac{H_{12}-e^{-j k s}}{e^{j k s}-H_{12}} e^{j 2 k(h+s)}
$$

yang dalam hal inikmerupakan bilangan gelombang, $h$ adalah jarak mikrofon 1 ke sampel uji dan $s$ adalah jarak antar mikrofon. Sehingga dengan demikian diperoleh nilai koefisien serapan bunyi,

$$
\alpha=1-|R|^{2}
$$




\section{HASIL DAN PEMBAHASAN}

\section{Modifikasi Permukaan dengan Prisma Tertutup}

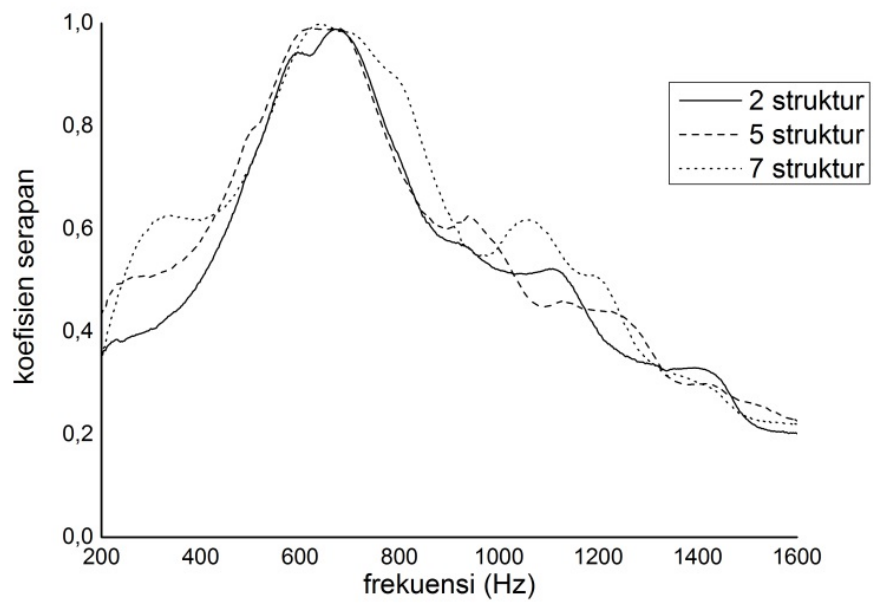

Gambar 4. Keoefisien Serap Bunyi Elemen Peredam Berbentuk prisma

Hasil pengujian koefisien serapan bunyi terhada elemen peredam dengan modifikasi permukaan berupa prisma tertutup disajikan pada Gambar 4. Tampak bahwa elemen peredam bekerja dengan baik pada bentang frekuensi yang sempit antara $400 \mathrm{~Hz}$ hingga $800 \mathrm{~Hz}$ dengan koefisien serapan berada dalam kisaran 0,5 hingga mendekati 1.

Gejala yang menarik tampak pada bentang frekuensi $200 \mathrm{~Hz}$ hingga $400 \mathrm{~Hz}$. Terjadi peningkatan kinerja serapan beriringan dengan bertambahnya jumlah struktur prisma yang terpasang pada permukaan elemen peredam.

Perubahan kinerja pada bentang frekuensi rendah ini dipicu oleh dua mekanisme berbeda. Pertama, konfigurasi struktur prisma tertutup menghasilkan efek hamburan meski tidak terlampau signifikan. Hal ini ditandai dengan perubahan nilai serapan pada bentang frekuensi antara $800 \mathrm{~Hz}$ hingga $1,3 \mathrm{kHz}$. Hal ini dapat difahami karena memang masingmasing prisma pada setiap konfigurasi memiliki dimensi, tinggi dan bentuk yang sama persis. Kedua, perbaikan kinerja di bentang frekuensi di bawah $200 \mathrm{~Hz}$ terpicu karena kombinasi antara elemen dasar peredam yang bentuk kubus dan struktur prisma yang terpasang di atasnya bekerja secara serempak membentuk struktur rongga tergandeng. Ketika jumlah struktur prisma bertambah, maka terjadi peningkatan bersifat akumulatif pada volume total struktur prisma yang kemudian terkopel dengan rongga elemen peredam. Akibatnya terjadi peningkatan kinerja serapan pada bentang frekuensi di bawah $200 \mathrm{~Hz}$ namun tidak mengubah bentang serapan maksimum di antara $400 \mathrm{~Hz}$ hingga 800 Hz. Dalam hal ini sifat elastik dari bahan penyusun berupa yellow board juga berkontribusi menghasilkan perubahan pada reaktansi struktur terkopel tersebut, serta memberi dampak pula pada perubahan kinerja pada bentang frekuensi di atas $800 \mathrm{~Hz}^{[17]}$.

\section{Modifikasi Permukaan dengan Prisma Terbuka}

Hasil pengujian dengan modifikasi permukaan dengan menggunakan prisma terbuka disajikan dalam Tabel 2. Selain terjadi peningkatan kinerja serapan terjadi pula pelebaran area serapan efektif pada semua konfigurasi yang dijuji. Kinerja serapan yang semula mengalami penurunan pada bentang frekuensi di atas $800 \mathrm{~Hz}$ pada pengujian dengan struktur prisma tertutup meningkat secara signifikan. Sebagaimana disajikan dalam Gambar 5 hingga Gambar 7, modifikasi permukaan dengan struktur prisma terbuka mampu memperbaiki nilai koefisien serapan dalam kisaran 0,86 hingga 0,95 pada bentang 
frekuensi $800 \mathrm{~Hz}$ hingga 1,25 Khz. Nilai tersebut jauh lebih besar dibandingkan dengan apa yang teramati pada modifikasi dengan strukut prisma tertutup.

Namun demikian, peningkatan kinerja serapan pada bentang frekuensi $800 \mathrm{~Hz}-1,25 \mathrm{kHz}$ diikuti pula oleh penurunan kinerja serapan di bentang di bawah $200 \mathrm{~Hz}$. Dalam hal ini koefisien serapan bernilai lebih kecil dari pada parameter yang sama yang terukur dalam pengujian dengan struktur prima tertutup.

Perubahan kinerja elemen peredam sebagaimana tersebut di atas diduga terjadi dengan mekanisme sebagai berikut. Ketika struktur prisma terbuka dipasang pada elemen peredam maka secara akustik keduanya membentuk sebuah resonator Helmholtz dengan dua lubang identik yang tepasang seolah membentuk leher mendatar di bagian atas rongga. Keadaan ini menghadirkan respon yang menyerupai perilaku resonator setengah panjang gelombang. Akibatnya, terjadi peningkatan jumlah massa yang yang berosilasi di bagian struktur leher resonator yang memicu peningkatan peredaman viskous dan secara bersamaan muncul pula resonansi oleh resonator setengah panjang gelombang tersebut. Mekanisme inilah yang kemudian berkontribusi terhadap peningkatan nilai koefisien serapan di bentang frekuensi tinggi di bentang $800 \mathrm{~Hz}$ hingga $1,25 \mathrm{kHz}$.

Adapun penurunan kinerja serapan pada bentang frekuensi di bawah $200 \mathrm{~Hz}$ diduga berkaitan dengan hilangnya efek kopel ketika struktur prisma dan elemen peredam membentuk satu rongga bersama. Perubahan nilai reaktansi yang semula meningkat akibat kontribusi kekakuan bahan penyusun yang memisahkan rongga elemen peredan dengan rongga struktur prisma tertutup tidak terjadi pada keadaan pengujian dengan prisma terbuka. Sementara itu penggabungan elemen peredam dan struktur prima tidak memberikan perubahan volume rongga secara signifikan. Dengan demikian, keadaan yang semula muncul akibat dipicu oleh mekanisme resonansi Helmholtz pada rongga terkopel dalam pengujian dengan prisma tertutup tidak terjadi pada pengujian dengan prisma terbuka. Adapun mekanisme hamburan masih terjadi sebagaimana yang berlaku pada keadaan pengujian dengan struktur prisma tetutup.

Tabel 2. Hasil Pengujian Koefisien Serap Peredam

\begin{tabular}{ccccccc}
\hline \multirow{2}{*}{$\begin{array}{c}\text { Frekuensi } \\
(\mathrm{Hz})\end{array}$} & \multicolumn{2}{c}{2 puncak } & \multicolumn{2}{c}{5 puncak } & \multicolumn{2}{c}{7 puncak } \\
\cline { 2 - 7 } & $\begin{array}{c}\text { Resonator } \\
\text { tertutup }\end{array}$ & $\begin{array}{c}\text { Resonator } \\
\text { terbuka }\end{array}$ & $\begin{array}{c}\text { Resonator } \\
\text { tertutup }\end{array}$ & $\begin{array}{c}\text { Resonator } \\
\text { terbuka }\end{array}$ & $\begin{array}{c}\text { Resonator } \\
\text { tertutup }\end{array}$ & $\begin{array}{c}\text { Resonator } \\
\text { terbuka }\end{array}$ \\
\hline 200 & 0,35 & 0,08 & 0,43 & 0,09 & 0,34 & 0,08 \\
250 & 0,38 & 0,16 & 0,50 & 0,17 & 0,52 & 0,17 \\
315 & 0,41 & 0,25 & 0,51 & 0,25 & 0,61 & 0,25 \\
400 & 0,50 & 0,34 & 0,57 & 0,36 & 0,61 & 0,35 \\
500 & 0,72 & 0,56 & 0,79 & 0,59 & 0,72 & 0,58 \\
630 & 0,94 & 0,85 & 0,98 & 0,92 & 0,99 & 0,90 \\
800 & 0,73 & 0,86 & 0,71 & 0,72 & 0,88 & 0,78 \\
1000 & 0,52 & 0,90 & 0,56 & 0,84 & 0,56 & 0,84 \\
1250 & 0,35 & 0,68 & 0,42 & 0,93 & 0,42 & 0,95 \\
1600 & 0,20 & 0,51 & 0,22 & 0,31 & 0,21 & 0,36 \\
\hline
\end{tabular}




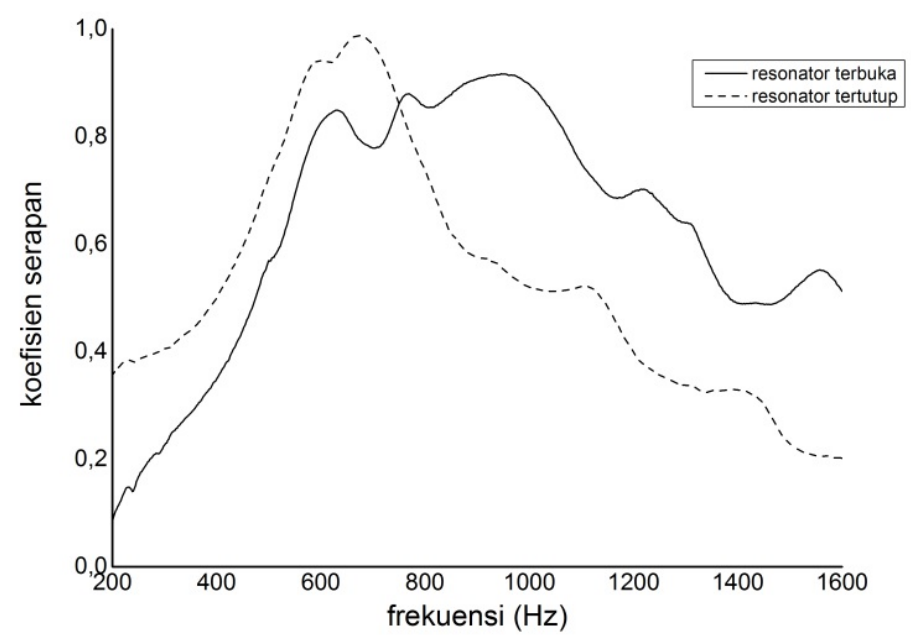

Gambar 5. Kinerja Peredam 2 Element

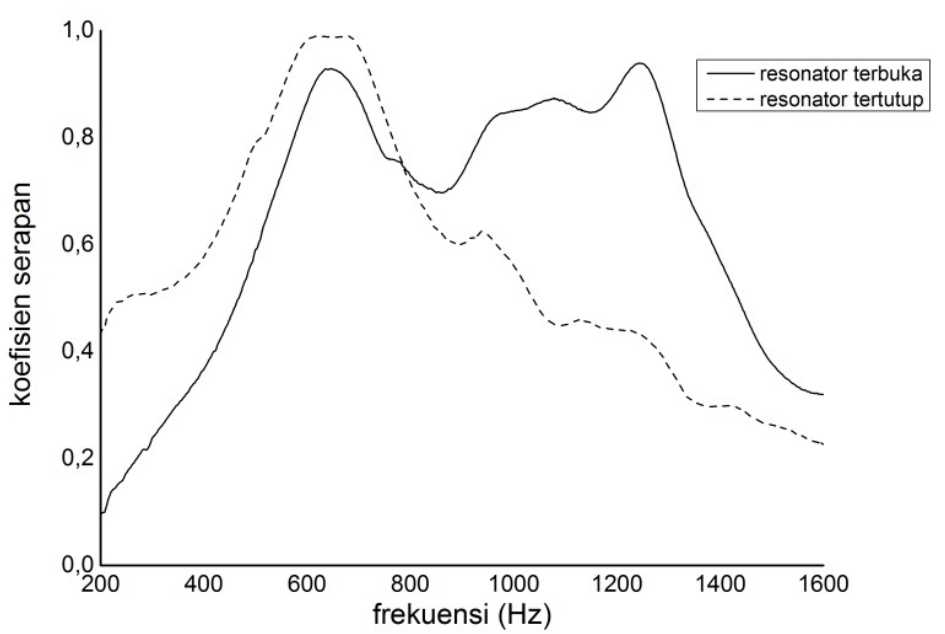

Gambar 6. Kinerja Peredam 5 Element

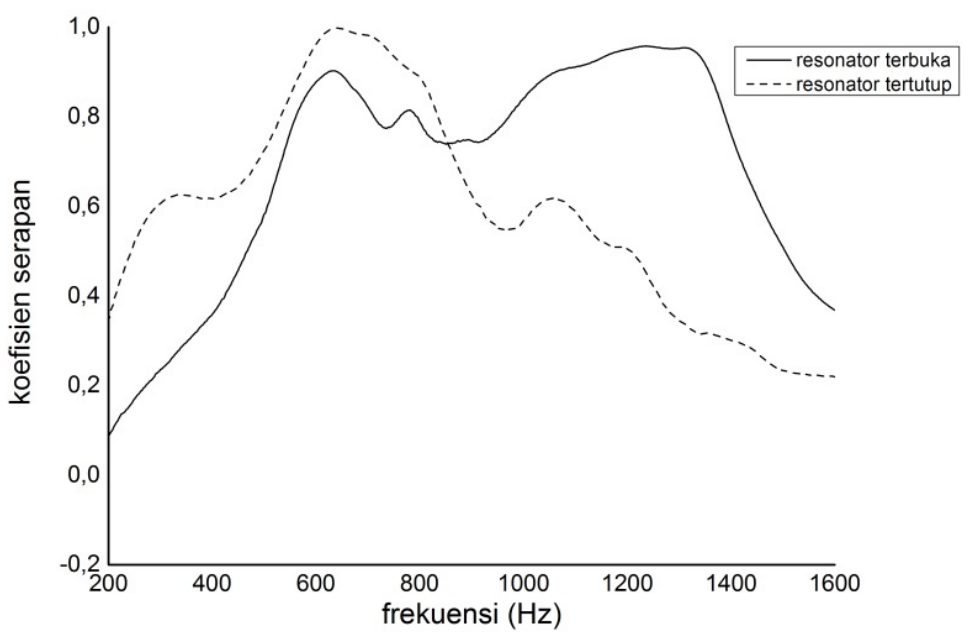

Gambar 7. Kinerja Peredam 7 Element

Hasil pengujian modifikasi permukaan pada kedua ragam struktur prisma menunjukkan bahwa pemakaian rongga terkopel dengan sekat berupa bahan dengan kekakuan tertentu dapat memicu peningkatan koefisien serapan di bentang frekuensi rendah di bawah 200 Hz. Di sisi lain, respon oleh struktur yang berprilaku seperti resonator setengah panjang gelombang bersama-sama dengan mekanisme resonansi Helmholtz oleh rongga elemen 
peredam dapat memperlebar bentang serapan efektif di bentang frkuensi menengah dan frekuensi tinggi antara $500 \mathrm{~Hz}$ hingga $1,25 \mathrm{kHz}$.

Temuan ini memberikan pemahaman bahwa teknik modifikasi permukaan dengan pemakaian struktur berbentuk prisma memiliki peluang yang sangat baik untuk diterapkan dalam pengembangan sound diffuser. Penurunan kinerja serapan di bentang frekuensi rendah pada pemakaian struktur prisma terbuka dapat diatasi dengan melakukan modifikasi pada gabungan rancangan prisma dan elemen peredam.

Modifikasi yang disarankan adalah dengan memasang struktur berupa leher yang memanjang ke dalam pada elemen peredam kemudian prisma dengan dua sisi terbuka disatukan di atasnya. Dengan demikian, elemen peredam akan menghadirkan perilaku resonansi yang bergeser ke frekuensi yang lebih rendah sebagai fungsi panjang leher, sementara resonansi oleh resonator setengah panjang gelombang dari prisma terbuka dapat dipertahankan.

\section{KESIMPULAN}

Modifikasi permukaan dengan penambahan struktur berbentuk prisma mampu memperbaiki kinerja elemen peredam. Perilaku sebagai struktur rongga tergandeng terpicu pada pemakaian prisma tertutup. Sifat elastik dari bahan penyusun berdampak pada perubahan reaktansi struktur terkopel yang memperbaiki kinerja serapan di frekuensi rendah di bawah $200 \mathrm{~Hz}$. Adapun untuk prisma terbuka, muncul respon dari prisma yang berprilaku sebagai resonator setengah panjang gelombang. Dampaknya timbul peningkatan signifikan pada bentang frekuensi tinggi antara $800 \mathrm{~Hz}$ hingga $1,25 \mathrm{kHz}$.

\section{DAFTAR PUSTAKA}

1. Cox, T.J. and d'Antonio, P.D. 2004. Acoustics Absorbers and Diffusers, Theory, Design and Application. Spon Press.

2. Berkhout, A. J., Palthe, D. W. W., and de Vries, D. 1979. Theory of optimal plane diffuser. Journal of Ac. Soc. Am., Vol. 65, No. 5, pp. 1334-1336.

3. Pogson, M. A., Whittaker, D. M., Gehring, G. A., Cox, T. J., Hughes, R. J., and Angus, J. A. S. 2010. Diffusive benefits of cylinders in front of Schroeder diffuser. Journal of Ac. Soc. Am., Vol. 128, No. 3, pp. 1149-1154.

4. Yang, J., Shen, Y., and Wang, H. 2006. On the Sound Absorption of Quadratic Residue Diffuser Groups with Various Shape and Combinations. Journal of Ac. Soc. Am., Vol. 119, No. 6, pp. 3546-3548.

5. Nutter, D. B., Leishman, T. W., Sommerfeldt, S. D., and Blotter, J. D. 2007. Measurement of sound power and absorption in reverberation chamber using energy density. Journal of Ac. Soc. Am., Vol. 121, No. 5, pp. 2700-2710.

6. Hanyu, T. 2010. A theoretical framework for quantitativel characterizing sound field diffusion based on scattering coefficient and absorption coefficient of walls. Journal of Ac. Soc. Am., Vol. 128, No. 3, pp. 1140-1148.

7. Groby, J. P., Duclos, A., Dazel, O., Boeckx, L., and Lauriks, W. 2011. Absorption of rigid frame porous layer with periodic circular inclusion backed by a periodic grating. Journal of Ac. Soc. Am., Vol. 129, No. 5, pp. 3035-3046.

8. Maa, D. Y. 1957. Theory and design of microperforated panel sound absorbing. Combustion, Scienta Sinica XVIII, pp. 55-71

9. Kamila, Z., Yahya, I., dan Utari. 2014. Pengaruh Fraksi Abu Onggok Aren dan Konfigurasi Resonator pada Kinerja Serapan Akustik Batako Ekspose. Indonesian Journal of Applied Physics, Vol. 04, No.1, Hal. 19. ISSN: 2089 - 0133. 
10. Kristiani, R., Yahya, I., dan Harjana. 2014. Kinerja Serapan Bunyi Komposit Ampas Tebu Berdasarkan Variasi Ketebalan dan Jumlah Quarter Wavelength Resonator terhadap Kinerja Bunyi. Jurnal Fisika dan Aplikasinya, Vol 10, No. 1. ISSN: 1858036X.

11. Harjana, and Yahya, I. 2014. Perforated Flexible Membrane Insertion Influence on The Sound Absorption Performance of Cavity Backed Micro Perforated Panel. 7th International Conference on Physics and Its Applications.

12. Yahya, I. and Harjana. 2013. New sound absorption improvement strategy for QRD element. Proceeding of 20th International Conference on Sound and Vibration, ICSV20, Bangkok (Thailand), July 2013.

13. Selamet, A. and Lee, I. 2003. Helmholtz Resonator with Extended Neck. J. Acoust. Soc. Am., Vol. 113, No. 4.

14. Falsafi, I. and Ohadi, A. 2015. Improving Absorption Bandwidth of Microperforated Panel by Stepping the Cavity. Proceeding of 22th International Conference on Sound and Vibration, ICSV22, Florence (Italy), July 2015.

15. Wang, C., and Huang, L. 2011. On the acoustic properties of parallel arrangement of multiple micro-perforated panel absorbers with different cavity depths. J. Acoust. Soc. Am., Vol. 130, No. 1.

16. Vigran, T. E. Building Acoustics. Taylor \& Francis Group, 2008.

17. Seddeq, H. S. 2009. Factors Influencing Acoustics Performance of Sound Absorptive Materials. Australian Journal of Basic and Applied Sciences, Vol. 3, No. 4, pp. 46104617. ISSN: 1991-8178 